\title{
Addressing the "What do we have to lose? Just give the drug" rationale: making the case for clinical trials and against off-label use in COVID-19
}

\author{
Venktesh R. Ramnath ${ }^{1}$, Heather J. Zar ${ }^{2}$, Atul Malhotra ${ }^{1}$ \\ ${ }^{1}$ Division of Pulmonary, Critical Care, and Sleep Medicine, UC San Diego Health, La Jolla, CA, USA; ${ }^{2}$ Department of Paediatrics and Child Health, \\ and SA-MRC Unit on Child \& Adolescent Health, University of Cape Town and Red Cross War Memorial Children's Hospital, Cape Town, South \\ Africa \\ Correspondence to: Venktesh R. Ramnath. Division of Pulmonary, Critical Care, and Sleep Medicine, UC San Diego Health, La Jolla, CA, USA. \\ Email: vramnath@health.ucsd.edu. \\ Provenance and Peer Review: This article was commissioned by the editorial office, fournal of Thoracic Disease. The article was sent for external peer \\ review organized by the editorial office.
}

Submitted May 23, 2020. Accepted for publication Jun 05, 2020.

doi: 10.21037/jtd-20-2011

View this article at: http://dx.doi.org/10.21037/jtd-20-2011

As most countries continue to grapple with how to address COVID-19 illness most effectively, uncertainty about how best to diagnose and care for these patients has influenced treatment decisions of medical practitioners across the world. For example, observed variations in lung compliance in COVID pneumonia that were initially characterized as different phenotypes of lung injury [COVID-19 acute respiratory distress syndrome (ARDS) or "CARDS" (1)] have led to doubts about the use of ventilators $(2,3)$. Concerns about possible "cytokine release syndrome" have opened fresh discussions about the use of steroids and antiinflammatory agents in sepsis and ARDS. Controversy still surrounds use of dosages of anticoagulants, given concerns about hypercoagulable states and development of microthrombi. As a result, there is considerable confusion about how best to help patients overcome severe COVID-19 illness.

In this void, the appeal of unproven therapies has risen considerably, despite inconsistent evidence of benefit. Convalescent plasma proved ineffective in Ebola (4) and high-quality studies in other viral diseases [e.g., pandemic H1N1 influenza (5)] are lacking as all were observational and did not have control arms. One retrospective study of steroids early in clinical COVID-19 course suggested a positive response (6), but the true role of steroids in viral illness is unclear especially given previous evidence indicating increased mortality in influenza (7). Tocilizumab, an anti-interleukin-6 receptor monoclonal antibody currently being studied, continues to be used empirically for COVID-19 despite potential risks of intestinal perforation, cytopenia, and cytomegalovirus reactivation $(8,9)$. Hydroxychloroquine, a medication with reported in vitro activity against SARS-CoV2, has been especially popular $(10,11)$ despite the lack of clinical benefits (12). Indeed, the use of some of these therapies was facilitated by politicians trying to promote optimism as well as by governmental bodies like the FDA in the US under a "compassionate use" (National Expanded Access Treatment protocol) provision. The appeal of using unproven therapies has been furthered by challenges to rigorous study methodologies, as some have questioned the significance of randomized clinical trials in critical illness to assess outcomes (13). This has led to some practitioners to invoke a "what's there to lose?" rationale to justify off-label use of medications, such as tissue plasminogen activator (tPA) for suspected pulmonary microthrombi (14).

The use of unproven or repurposed therapies outside of robust clinical trials is problematic for several reasons. First and foremost, true scientific advances may be difficult or impossible to accomplish without proper examination in a clinical trial setting. While statistical methods and generalizability of study design should be examined when considering application of results in individual patients, randomized controlled trials and judicious control of risk 
of bias continue to buttress the foundation of medical science. Without equipoise, results of clinical trials may lack credibility. Second, many therapies have demonstrated real toxicity in COVID-19. Hydroxychloroquine, especially in conjunction with azithromycin, has been shown to increase risks of QT prolongation and cardiac arrhythmias (15), leading to new FDA warnings against its use for COVID-19. Further widespread use may lead to shortages of supply for those with other conditions in whom this therapeutic agent is effective and necessary such as many rheumatological conditions. Convalescent plasma, while generally tolerated, incurs risks of transfusion-associated circulatory overload and acute lung injury that can be difficult to appreciate in patients already suffering from severe COVID-19 ARDS. Steroids can prolong viral shedding times and worsen myopathies and dysglycemia, and tocilizumab can cause bone marrow suppression. Third, many novel therapies are expensive and limited in supply, leading to difficulties in access in many countries. For example, a lack of transparency that surrounds remdesivir distribution and availability has frustrated efforts to access the drug in the US (16). As a result, off-label use of unproven or repurposed therapies is fraught with risk.

Furthermore, specific challenges in low- and middleincome countries (LMICs) require attention. Most important, adoption of novel therapies detracts from efforts against health threats with pre-existing and currently high prevalence and associated mortality. A case in point is malaria, an infectious disease that still affects over 200 million people and causes 400,000 deaths annually in many LMICs, particularly in sub-Saharan Africa. Recent efforts to address COVID-19 have undermined malaria-prevention programs and reduced global supplies of chloroquine-based medications that are essential in battling malaria and other Plasmodial diseases. As a result, projections now suggest that the number of malaria cases will soon double (17), erasing gains made in disease control over the last 20 years. The situation is similar for tuberculosis (TB). The STOP TB partnership has estimated that a 3-month lockdown with a protracted restoration period could substantially increase the global incidence and deaths due to TB globally (18). Based on the Ebola experience, Matshido Moeti, the director of WHO in Africa, recently provided a cautionary note: "We saw with the Ebola virus disease outbreak in West Africa that we actually lost more people to diseases that we previously were managing to control like malaria than we lost to the outbreak itself. Let us not repeat that with COVID-19." (19). In addition, 50-70\% of deaths in LMICs are directly linked to the lack of basic, rather than novel, critical care resources such as oxygen, ICU personnel and beds, ventilators, medications, and access to transport (20), rather than novel therapies with unproven benefits. Lack of oxygen therapy is a key issue for many LMICs countries, and the COVID epidemic may offer an opportunity to undertake research on improved innovative methods for strengthening oxygen delivery (21). Given that the leading causes of death in LMICs across Asia and Africa continue to be ischemic heart disease, stroke, and lower respiratory tract infections such as TB and bacterial pneumonia (22), investment in these fundamental resources and programs is crucial. Expenses for obtaining, distributing, and administering novel but untested COVID-19 therapies divert resources away from basic critical care needs for medical conditions that are known to be treatable. Finally, excessive use of unproven or repurposed therapeutic agents may complicate global supply chains and embroil LMICs in geopolitical tensions. For example, the consumption and stockpiling of hydroxychloroquine in the US led to calls for increased exports of hydroxychloroquine from India, resulting in threats of political "retaliation" when India tried to restrict exports of the drug (23).

Clinicians in LMICs and high-income countries alike can leverage several strategies to help COVID-19 patients while also minimizing risks. First, effective practice of known principles and concepts of critical care medicine substantiated by years of study should be encouraged and enforced. Examples include high-flow oxygen delivery systems, low tidal volume ventilation in ARDS, protocolized interruptions of sedation and breathing trials in ventilated patients, early mobilization, and attention to appropriate pain, agitation, and delirium assessments and treatments, many of which are part of the ABCDEF bundle $(24,25)$. Second, recognition of the importance of high-quality clinical trials and equipoise is essential to make sustainable scientific advances. In situations in which enthusiasm is high but resources for research are limited, countries can restrict involvement in clinical trials to certain therapies of higher interest, thereby containing total expenditures while still participating in scientific advancement. Research must be appropriate to the population and needs, and the COVID pandemic may offer opportunities for LMICs to undertake research of broad value to health beyond COVID. Once obtained, clinical trial results should be shared with the medical community and public as transparently, quickly, and widely as possible. Third, research must be conducted in concert with awareness and compliance with basic infection control measures that provide high-yield and cost-effective 
benefits. For example, hand hygiene is directly associated with reductions in disease transmission in COVID-19 (26), and measures like environmental decontamination and universal use of masks are low-cost and effective to prevent transmission. Proper use of personal protective equipment (e.g., mask, gowns, and face shields) has been shown to be effective, particularly in aerosol-generating procedures such as bronchoscopy and intubation (27). Finally, we must carry a sense of perspective, calm, and humility in the face of this crisis that will facilitate rational decision-making. Anxiety due to uncertainty, fear of infection, and frustration is an understandable and natural human response to crisis. However, by focusing energies upon substantiated evidence and in high-quality clinical trials to evaluate novel therapies rather than using them at will, clinicians can direct resources and expertise towards the advancement of medical science that will ultimately achieve the best outcomes in COVID-19 and other diseases.

\section{Acknowledgments}

Funding: None.

\section{Footnote}

Conflicts of Interest: All authors have completed the ICMJE uniform disclosure form (available at http://dx.doi. org/10.21037/jtd-20-2011). AM is funded by the National Institutes of Health. He reports income from Merck and Livanova related to medical education. ResMed provided a philanthropic donation to UC San Diego. AM serves as an unpaid editorial board member of Fournal of Thoracic Disease from Jul 2015 to Jun 2021. The other authors have no conflicts of interest to declare.

Ethical Statement: The authors are accountable for all aspects of the work in ensuring that questions related to the accuracy or integrity of any part of the work are appropriately investigated and resolved.

Open Access Statement: This is an Open Access article distributed in accordance with the Creative Commons Attribution-NonCommercial-NoDerivs 4.0 International License (CC BY-NC-ND 4.0), which permits the noncommercial replication and distribution of the article with the strict proviso that no changes or edits are made and the original work is properly cited (including links to both the formal publication through the relevant DOI and the license).
See: https://creativecommons.org/licenses/by-nc-nd/4.0/.

\section{References}

1. Gattinoni L, Chiumello D, Caironi P, et al. COVID-19 pneumonia: different respiratory treatments for different phenotypes? Intensive Care Med 2020. [Epub ahead of print]. doi: 10.1007/s00134-020-06033-2.

2. Richardson S, Hirsch JS, Narasimhan M, et al. Presenting Characteristics, Comorbidities, and Outcomes Among 5700 Patients Hospitalized With COVID-19 in the New York City Area. JAMA 2020;323:2052-9.

3. Some Doctors Pull Back on Using Ventilators to Treat Covid-19 - WSJ [Internet]. [cited 2020 May 19]. Available online: https://www.wsj.com/articles/some-doctors-pullback-on-using-ventilators-to-treat-covid-19-11589103001

4. van Griensven J, Edwards T, de Lamballerie X, et al. Evaluation of Convalescent Plasma for Ebola Virus Disease in Guinea. N Engl J Med 2016;374:33-42.

5. Hung IF, To KK, Lee CK, et al. Convalescent Plasma Treatment Reduced Mortality in Patients With Severe Pandemic Influenza A (H1N1) 2009 Virus Infection. Clin Infect Dis 2011;52:447-56.

6. Wu C, Chen X, Cai Y, et al. Risk Factors Associated With Acute Respiratory Distress Syndrome and Death in Patients With Coronavirus Disease 2019 Pneumonia in Wuhan, China. JAMA Intern Med 2020;e200994. [Epub ahead of print]. doi:10.1001/jamainternmed.2020.0994.

7. Moreno G, Rodríguez A, Reyes LF, et al. Corticosteroid treatment in critically ill patients with severe influenza pneumonia: a propensity score matching study. Intensive Care Med 2018;44:1470-82.

8. Komura T, Ohta H, Nakai R, et al. Cytomegalovirus Reactivation Induced Acute Hepatitis and Gastric Erosions in a Patient with Rheumatoid Arthritis under Treatment with an Anti-IL-6 Receptor Antibody, Tocilizumab. Intern Med 2016;55:1923-7.

9. Ogata A, Kato Y, Higa S, et al. IL-6 inhibitor for the treatment of rheumatoid arthritis: A comprehensive review. Mod Rheumatol 2019;29:258-67.

10. Liu J, Cao R, Xu M, et al. Hydroxychloroquine, a less toxic derivative of chloroquine, is effective in inhibiting SARS-CoV-2 infection in vitro. Cell Discov 2020;6:16.

11. FDA. Fact sheet for health care providers: emergency use authorization (EUA) of hydroxychloroquine sulfate supplied from the strategic national stockpile for treatment of COVID-19 in certain hospitalized patients. [Internet]. Available online: https://www.fda.gov/media/136537/ 
download

12. Rosenberg ES, Dufort EM, Udo T, et al. Association of Treatment With Hydroxychloroquine or Azithromycin With In-Hospital Mortality in Patients With COVID-19 in New York State. JAMA 2020. [Epub ahead of print].

13. Girbes ARJ, de Grooth HJ. Time to stop randomized and large pragmatic trials for intensive care medicine syndromes: the case of sepsis and acute respiratory distress syndrome. J Thorac Dis. 2020;12:S101-9.

14. Doctor gambles on clot-busting drug to save virus patients [Internet]. [cited 2020 May 18]. Available online: https:// apnews.com/5c0dc863f214d32a53c6280c31cf3f56

15. Chorin E, Dai M, Shulman E, et al. The QT interval in patients with COVID-19 treated with hydroxychloroquine and azithromycin. Nat Med 2020. [Epub ahead of print]. doi:10.1038/s41591-020-0888-2.

16. Health-Care Leaders Question How Remdesivir Is Being Distributed - WSJ [Internet]. [cited 2020 May 18]. Available online: https://www.wsj.com/articles/ health-care-leaders-question-how-remdesivir-is-beingdistributed-11588889219

17. Malaria could be about to make a comeback - and the coronavirus is to blame [Internet]. World Economic Forum. [cited 2020 May 18]. Available online: https:// www.weforum.org/agenda/2020/04/malaria-treatmentrise-africa-coronavirus/

18. The Potential Impact of the COVID-19 Response on Tuberculosis in High-Burden Countries: a modelling analysis. [Internet]. Available online: http://www.stoptb. org/assets/documents/news/Modeling\%20Report_1\%20 May\%202020_FINAL.pdf

19. Coronavirus fight risks setting malaria progress back two decades, WHO says [Internet]. BusinessLIVE. [cited 2020 May 18]. Available online: https://www.businesslive.co.za/ bd/national/health/2020-04-23-coronavirus-fight-risks-

Cite this article as: Ramnath VR, Zar HJ, Malhotra A. Addressing the "What do we have to lose? Just give the drug" rationale: making the case for clinical trials and against off-label use in COVID-19. J Thorac Dis 2020;12(6):3031-3034. doi: $10.21037 /$ jtd-20-2011 setting-malaria-progress-back-two-decades-who-says/

20. Murthy S, Adhikari NK. Global health care of the critically ill in low-resource settings. Ann Am Thorac Soc 2013;10:509-13.

21. Duke T, Graham SM, Cherian MN, et al. Oxygen is an essential medicine: a call for international action. Int $\mathrm{J}$ Tuberc Lung Dis 2010;14:1362-8.

22. Dahn CM, Wijesekera O, Garcia GE, et al. Acute care for the three leading causes of mortality in lower-middleincome countries: A systematic review. Int J Crit Illn Inj Sci 2018;8:117-42.

23. India agrees to release unproven "corona drug." BBC News [Internet]. 2020 Apr 7 [cited 2020 May 19]; Available online: https://www.bbc.com/news/world-asiaindia-52196730

24. Ely EW, LamasBioBioFollowFollow closeE WEL closeDaniela. Perspective I ICU doctors already know how to get covid-19 patients off ventilators faster [Internet]. Washington Post. [cited 2020 May 18]. Available online: https://www.washingtonpost.com/outlook/2020/04/10/ ventilators-icu-safety-bundle/

25. Pun BT, Balas MC, Barnes-Daly MA, et al. Caring for Critically Ill Patients with the ABCDEF Bundle: Results of the ICU Liberation Collaborative in Over 15,000 Adults. Crit Care Med 2019;47:3-14.

26. Ran L, Chen X, Wang Y, et al. Risk Factors of Healthcare Workers with Corona Virus Disease 2019: A Retrospective Cohort Study in a Designated Hospital of Wuhan in China. Clin Infect Dis 2020; ciaa287. [Epub ahead of print]. doi:10.1093/cid/ciaa287

27. Chu DK, Akl EA, Duda S, et al. Physical distancing, face masks, and eye protection to prevent person-to-person transmission of SARS-CoV-2 and COVID-19: a systematic review and meta-analysis. Lancet 2020. [Epub ahead of print]. 